\section{BLUMENAU E SEUS IMIGRANTES: APONTAMENTOS ACERCA DA EMERGÊNCIA DE UMA CULTURA FÍSICA (1850-1899)}

\author{
BLUMENAU AND ITS IMMIGRANTS: NOTES ABOUT THE EMERGENCE OF A \\ PHYSICAL CULTURE (1850-1899)
}
BLUMENAU Y SUS INMIGRANTES: APUNTES ACERCA DE LA EMERGENCIA
DE UNA CULTURA FÍSICA (1850-1899)

Heitor Luiz Furtado*, Evelise Amgarten Quitzau**, Marcelo Moraes e Silva*
Palavras chave:

Grupos étnicos.

Migração.

Sociedades.

História.

\begin{abstract}
Resumo: Situada no nordeste de Santa Catarina, na região do Vale do Itajaí, Blumenau é conhecida em todo o Brasil como uma das cidades com maior influência germânica em sua cultura e história. Nesse sentido, o presente ensaio foi norteado pela seguinte questão: como os clubes de tiro foram utilizados pelos imigrantes para a emergência de uma cultura física na cidade de Blumenau? As análises realizadas apontam para a centralidade dos Schützenvereine enquanto espaços importantes para o desenvolvimento e cultivo de tradições de práticas corporais trazidas do velho continente, bem como para a formação de importantes dispositivos para consolidação de uma cultura física por parte dos habitantes de Blumenau.
\end{abstract}

Abstract: Located on the northeast of Santa Catarina, in the Itajai Valley, Blumenau is known in Brazil as one of the cities with greater German influence over its culture and history. Therefore, the following question guides this essay: how did German immigrants use shooting clubs as a means for the emergence of a physical culture in the city? The analyses point to the centrality of the Schützenvereine as important spaces to develop and cultivate traditions and bodily practices brought from the old continent as well as to establish important devices for consolidation of a physical culture by part of Blumenau's residents.

Resumen: Ubicada en el noreste de Santa Catarina, en el Valle del Itajaí, Blumenau es conocida en todo Brasil como una de las ciudades con mayor influencia germana en su cultura e historia. En ese sentido, el presente ensayo ha sido orientado por la siguiente pregunta: ¿cómo fueron utilizados los clubes de tiro por los inmigrantes para la emergencia de una cultura física en la ciudad de Blumenau? Los análisis realizados indican la centralidad de los Schützenvereine como espacios importantes para el desarrollo y cultivo de tradiciones de prácticas corporales traídos del viejo continente, así como para la formación de importantes dispositivos para la consolidación de una cultura física por parte de los habitantes de Blumenau.
*Universidade Federal do Paraná. Curitiba, PR, Brasil. E-mail: heitorluizfurtado@ hotmail.com; moraes_marc@yahoo.com.br

**Universidad de la República de Uruguay. Paysandú, Uruguai. E-mail: eveliseaq @yahoo.com.br

Recebido em: 09-04-2018 Aprovado em: 23-05-2018

DOI: http://dx.doi.org/10.22456/1982-8918.81849 (c) (1) (8) Licence 


\section{INTRODUÇÃOO}

Situada no nordeste de Santa Catarina, na região do Vale do Itajaí, Blumenau é conhecida em todo o Brasil como uma das urbanidades com maior influência germânica em sua cultura. Para Machado (2011), a cidade atualmente é interpretada como um espaço cultural, contendo elementos identitários que constituíram a localidade a partir das relações entre imigração, trabalho, raízes e tradições. Ao circular por Blumenau nos dias atuais, ainda são constantes as referências e alusões deixadas e reelaboradas por esta "tradição inventada"', fruto de um processo imigratório marcantemente alemão que é presente, vivo e cultivado pela população, e, portanto, vários são os indícios das tradições alemãs. Podem ser citados como elementos enraizados na cultura local os diferentes sotaques da língua germânica, a Oktoberfest, comemoração anual conhecida nacionalmente, as roupas, trajes e danças típicos, bem como os Clubes de Caça e Tiro.

A fundação da Colônia Blumenau situa-se em um movimento mais amplo das chegadas dos primeiros imigrantes alemães ao Brasil e à então província de Santa Catarina. SegundoLuebke (1987), Seyferth (1994) e Quitzau (2016), o ano de 1824 é considerado o marco inicial da imigração alemã, com a criação do primeiro núcleo germânico na cidade de São Leopoldo, no estado do Rio Grande do Sul. Já em Santa Catarina, a chegada ocorreu em1829, na Colônia de São Pedro de Alcântara, atual região da grande Florianópolis, a qual não obteve sucesso devido à localização inadequada e ao despreparo dos imigrantes para a vida rural, o que culminou na procura por áreas mais favoráveis na localidade. Nesse segmento, outras colônias, como Blumenau e Joinville, obtiveram êxitos em seus processos de desenvolvimento, por conta das condições geográficas e climáticas.

Neste contexto, foi no ano de 1850 que se iniciou o processo de fundação da Colônia Blumenau por Hermann Bruno Otto Blumenau. Dr. Blumenau, como era conhecido, chegou ao local com mais dezessete imigrantes alemães, marcando oficialmente a colonização do Vale do Itajaí, tendo encontrado na região boas condições para a instalação da colônia, principalmente, pela fertilidade do solo e por sua localização geográfica, às margens do Rio Itajaí-Açu. Inicialmente, em condição de colônia particular, a comunidade passou por inúmeras dificuldades e somente em 1860 Blumenau passou à categoria de colônia do governo brasileiro, recebendo, com isso, recursos e investimentos. Tal mudança culminou em considerável crescimento no número de imigrantes e no seu maior desenvolvimento (HOFFMANN; MELO, 2014; PETRY, 1988; ROSSBACH, 2008; SEYFERTH, 1994; 2004).

Sendo assim, Blumenau foi se desenvolvendo aos poucos, e seus habitantes, majoritariamente alemães, se adaptaram ao clima e às condições de vida no novo continente. Esse processo trouxe consigo a entrada de novos hábitos, costumes e crenças, que se materializaram nas vestimentas, nos modos de viver e se comportar, bem como na emergência de novas formas de divertimentos. Uma característica importante dos imigrantes alemães, apontada por Seyferth (2004) e Quitzau (2016), se propunha a suprir as demandas não atendidas pelos governos, e concretizou-se em um movimento de fundação de associações com diversas finalidades como beneficentes, religiosas, educacionais e recreativas. Em meio às tradições germânicas trazidas pelos imigrantes, destacam-se, por exemplo, uma

1 Hobsbawm e Ranger (1997) entendem tradição inventada como um conjunto de práticas subentendidas e/ou abertamente aceitas. Ações 
das festas mais populares, a Schützenfest, celebração dos atiradores, que evidenciava as velhas tradições de tiro ao alvo, que eram realizadas nos clubes de tiro, conhecidos como Schützenvereine.

A transformação da pequena colônia, através do crescimento da população, acarretou a construção de moradias, surgimento de pequenos comércios, novos espaços de convívio social, diferentes formas de relacionamentos, dentre outros elementos que levaram a importantes mudanças nos modos de agir, se comportar e de se relacionar dos blumenauenses.

Essas rupturas e continuidades pelas quais as cidades brasileiras passaram têm sido objetos de pesquisas que buscam identificar e analisar esses processos, tomando como principal eixo de análise questões vinculadas à educação do corpo e à disseminação das práticas esportivas. Nesta perspectiva, Moraes e Silva (2011) buscou analisar o surgimento de um dispositivo esportivo na cidade de Curitiba entre os anos de 1899 e 1918.0 autor apontou elementos centrais das transformações dos divertimentos, o que culminou com o processo de esportivização de algumas práticas corporais. Seus achados em Curitiba oportunizam reflexões importantes ao contexto blumenauense, principalmente pelas transformações históricas e as relações entre a cidade catarinense e seus imigrantes alemães, visto que essas metamorfoses são indícios importantes na medida em que se relacionam a diferentes aspectos da vida, perpassando por distintos modos de agir, de se comportar e de se divertir. A forte presença dos Clubes de Caça e Tiro e das Associações Ginásticas no processo de desenvolvimento de Blumenau pode se tornar fonte de análises e oferecer elementos interessantes sobre o cultivo de uma cultura física nas primeiras décadas do século XX no Brasil.

Neste sentido, o presente ensaio é norteado pela seguinte questão: como os clubes de tiro foram utilizados pelos imigrantes para a emergência de uma cultura física em Blumenau? Objetiva-se analisar o surgimento e crescimento da cidade, notadamente no que concerne às reflexões empreendidas acerca da emergência de uma cultura física, tomando como elemento central os Clubes de Caça e Tiro.

\section{NOVAS FORMAS DE SE COMPORTAR E DE SE RELACIONAR: O CONCEITO DE CULTURA FÍSICA}

A partir de um determinado período histórico marcadamente caracterizado pelo processo imigratório, levantam-se as seguintes indagações: quais contribuições o conceito de cultura física pode fornecer para a ampliação do olhar acerca do desenvolvimento da cidade? De que maneira esse conceito amplo se relaciona com Blumenau, notadamente em seus primeiros 50 anos de existência? Quais são os elementos que apontam para a emergência de uma cultura física por parte dos habitantes daquela localidade? Qual a importância dos Schützenvereine para a emergência de uma cultura física nos habitantes de Blumenau?

Compreender esses questionamentos é uma empreitada complexa, pois vários elementos influenciam na análise. Toma-se como base o conceito de cultura física desenvolvido por Kirk (1999), tematizado posteriormente por Moraes e Silva (2011) e Scharagrodsky (2014), os quais o compreendem como uma complexa rede de significados que permite a análise multidimensional que ultrapassa a dimensão biológica em que, na maioria das vezes, são pensadas as distintas práticas corporais. A definição oportuniza a operação com discursos sobre o corpo a partir de três formas: divertimentos, ginásticas e esportes. A cultura física deve 
ser pensada e interpretada a partir de um amplo conjunto de transformações sociais, políticas, econômicas e demográficas vinculadas a um determinado espaço e temporalidade específica.

Para Kirk (1999), Moraes e Silva (2011) e Scharagrodsky (2014), o termo cultura física permite operar com discursos e práticas centrados no corpo, possibilitando a compreensão de certas relações sociais, econômicas, políticas, sexuais, éticas e morais que se configuram no passado e de alguma forma como seguem ou não se manifestando no presente. A cultura física permite identificar um amplo repertório de práticas e construções discursivas sobre o corpo, grupos sociais, indivíduos e instituições.

Para Scharagrodsky (2014), o termo cultura física está relacionado a sistemas modernos de exercícios físicos consolidados ao longo do século XIX, que se traduzem pela busca de uma simetria corporal e racionalização energética. As ginásticas, as danças, os jogos e os esportes foram mais do que apenas exercitações físicas, dado que carregam consigo traços importantes de um determinado período histórico.

Por Blumenau se ruma cidade cujo processo de fundação foi notadamente influenciado por imigrantes alemães, dentre as várias possibilidades de práticas corporais, salienta-se a criação de algumas associações recreativas, culturais e esportivas que contribuíram para a emergência de uma cultura física e acabaram ocupando centralidade na constituição da cidade. No meio desses espaços e instituições, destacam-se os Clubes de Tiro (Schützenvereine) enquanto locais que podem fornecem elementos importantes para o presente ensaio.

\section{OS CLUBES DE TIRO: LOCAIS PARA A EMERGÊNCIA DE UMA CULTURA FÍSICA EM BLUMENAU}

Pedrini e Martins (2004) apontam que a tendência dos imigrantes europeus radicados no sul do Brasil era a de viver em comunidade e formar associações. Rossbach (2008) indica que não somente os Clubes de Tiro ocuparam locais centrais na construção identitária dos imigrantes alemães, como também outros espaços tiveram centralidade, sendo estes os grupos de canto, teatrais, sociedades ginásticas e aquelas que divulgam a cultura e o entretenimento entre os imigrantes.

A formação de colônias alemãs em regiões restritas, como Blumenau, somada ao isolamento social e político, possibilitou a manutenção da cultura germânica. Porém, foi a partir da relação com o novo continente que os imigrantes reconstruíram sua identidade, designada como teuto-brasileira. Esta designação era atribuída a grupos de descendentes alemães que colonizaram, a partir do século XIX, principalmente os estados do sul do país, emergindo da ligação próxima com a noção de Volkstum, desenvolvida por Friedrich Ludwig Jahn, da qual deriva o termo Deutschtum (germanidade). Essa definição é resultado de um hibridismo cultural que contém uma duplicidade oriunda do contato entre os imigrantes e seus descendentes com a cultura brasileira (SEYFERTH, 2004; QUITZAU, 2012).

Cabe destacar que as primeiras associações destinadas à preservação da cultura alemã surgiram logo no início da colonização. Os Schützenvereine eram um tipo de espaço considerado, em seu início, utilitário e com raízes nacionalistas. Utilitário, visto que seus associados eram atiradores, formando uma espécie de defesa da colônia para o pequeno povoado, mas também era local de sociabilidade, encontros e relacionamentos. Além disso, era nacionalista, uma vez que as associações representavam a Volkstum (cultura popular) a partir 
do fortalecimento dos hábitos e costumes da velha pátria (SEYFERTH, 2004). Em síntese, para Assmann e Mazo (2012) a identidade teuto-brasileira apresenta-se como a reconstituição da identidade e preservação das tradições. Para isto, apropriaram-se de práticas culturais, como 0 tiro ao alvo, e acabaram por "inventar" uma nova tradição, buscando principalmente assegurar a continuidade do seu passado histórico.

Os Schützenvereine estavam presentes em todas as áreas nas quais houve a colonização alemã no sul do Brasil e tiveram importante papel na vida cultural dessas localidades. Suas práticas e disputas de tiro proporcionavam divertimentos, relações sociais, bem como a continuidade de tradições trazidas do velho continente. $O$ associativismo existente nos Clubes de Caça e Tiro tinha como fundamento a busca pela continuidade da cultura germânica, da consciência étnica e do uso do idioma alemão (ROSSBACH, 2008).

Fenômeno de grande profusão na Alemanha do século XIX, o associativismo buscou, em geral, romper barreiras estamentais, criando espaços de convívio para além daqueles representados pela família, Igreja e/ou trabalho, permitindo o estabelecimento de um novo espaço de debates que, ao mesmo tempo em que não pertencia à esfera do privado, também não estava diretamente sujeito ao controle estatal (NIPPERDEY, 1972). Sua expansão pelos territórios alemães, assim como as distintas finalidades para as quais as associações foram criadas (escolares, culturais, artísticas, de ginástica, de canto, de tiro), levam Nipperdey (1972) a considerar o associativismo como um dos movimentos mais marcantes da sociedade alemã daquele período.

No caso específico das sociedades de tiro, além de oferecerem possibilidades de divertimentos, estes espaços colaboravam com a polícia e o exército, cultivando o dever de se manter apto frente à iminência de qualquer ataque inimigo. As associações se constituíram como importantes locais de recreação, preservação e difusão da germanidade, além de compensação dos isolamentos nas quais muitas comunidades se encontravam, como era o caso de Blumenau (QUITZAU, 2016).

No início da Colônia de Blumenau os imigrantes eram carentes de qualquer convívio social, resumindo-se às palestras, visitas entre vizinhos e celebrações religiosas. Com o desenvolvimento da colônia às margens do Rio Itajaí-Açu, o distanciamento entre as pequenas casas, a vizinhança com a mata, as hostilidades e dificuldades das relações com os indígenas, os ataques de eventuais animais e as possibilidades de caça reforçaram e incentivaram o uso de armas de fogo. As idas ao centro da colônia, pelos indivíduos que moravam mais afastados, preferencialmente aos domingos e feriados para fazer compras e para festividades religiosas, eram regadas a desafios de pontaria. Disputas estas realizadas ao ar livre com alvos improvisados (PETRY, 1988).

Vigarello (2008), ao explorar o contexto europeu, indica que desde o século XVI as práticas de tiros eram comuns entre as comunidades e representavam objeto de festas, encontros, paradas e prêmios. Por meio da antiga tradição do tiro ao papagaio, pássaro de madeira, fixo no alto de um mastro, disputado pelos atiradores segundo uma ordem hierárquica, o encontro era interrompido quando se acertava o pássaro, e atribuído ao vencedor o título de rei. O historiador francês salienta que as práticas de tiro remontam à importância que os usos das armas de fogo tinham em determinados contextos sociais. Esses elementos indicam que as práticas de tiros circulavam em um contexto mais amplo na Europa e, por consequência, trazidos pelos imigrantes para o Brasil e cultivados na Colônia de Blumenau. 
Como salienta Vigarello (2008), diferente do esporte, que requer um conjunto unificado de comportamentos, um programa temporal e um sistema regulatório, nos jogos, tratando-se das práticas de tiro, qualquer terreno pode parecer propício e se tornar um local adequado para sua realização. Tais práticas não podem ser consideradas ainda como esporte, pois não apresentam um dispositivo institucional e nem uma organização seletiva. Esses jogos de competição e/ou de prêmio traduzem um mundo dominado pelo tempo do trabalho e/ou religioso, no qual o lúdico se inclui, algumas vezes sem previsão no espaço social e com regularidade nas festas do calendário, especialmente aquelas de caráter religioso.

A trajetória de alguns destes jogos, como os desafios de tiro, converge para uma história que leva em consideração os valores de determinadas sociedades, afetando e transformando profundamente a sensibilidade existente nestes jogos. A partir deste contexto, emergiu a necessidade da criação de espaços próprios, seguros e adequados para a realização das práticas de tiros. Moraes e Silva (2011) sublinha que um dos pontos que mais contribuiu para o crescimento das práticas esportivas foi justamente seu processo de institucionalização, primeiramente com o seu enclausuramento nos clubes e, posteriormente, com o surgimento das primeiras entidades burocráticas.

A inserção das práticas esportivas em um quadro de elementos regidos por uma instituição objetivava a produção de uma uniformidade nos comportamentos dos indivíduos frequentadores destes espaços, assumindo a necessidade de incorporação de determinadas regras de convívio social. Para Vigarello (2008),a institucionalização das práticas corporais inscreveu os movimentos corporais em um vasto conjunto de normas, dando-lhes uma regularidade e uma disciplina visual que até então não haviam sido vistas. Foram nestes espaços que começaram a desfilar corpos definidos por uma cultura física.

Esses espaços institucionais, mesmo com suas semelhanças ao esporte atual, através dos encontros competitivos organizados por instituições, agrupamentos temporários de competidores, regularidades das práticas, presença de espectadores e até mesmo por semelhanças visuais, apresentam sentidos e significados diferentes dos atuais. As práticas de tiro no início de Blumenau e o desenvolvimento de instituições para sua realização situavamse em um contexto muito mais de cultivo e preservação de uma identidade étnica do que propriamente para o desenvolvimento e aprimoramento de uma destreza corporal.

Por conseguinte, em 1859, apenas nove anos após a chegada dos primeiros imigrantes, foi fundado o primeiro Schützenverein de Blumenau e do Vale do Itajaí. Este tipo de espaço, como evoca Petry (1988), resolveu muitos problemas daquela sociedade, pois serviu de base para a formação social dos indivíduos. Tais estabelecimentos tinham uma maior importância no Brasil do que propriamente no antigo país dos imigrantes, formando, com a família e a lgreja (luterana e católica), a tríade da vida dos colonos teuto-brasileiros.

A opção pela sociedade de tiro veio pela herança social do imigrante. 0 constante uso da arma de fogo fez com que os praticantes do tiro recorressem ao Dr. Blumenau para a obtenção de um lugar adequado para este fim. É preciso destacar, como apontando por Petry (1988), que, após a doação do terreno para a instalação do que viria a ser a primeira sociedade recreativa de Blumenau, esse espaço foi frequentado por indivíduos que desfrutavam de prestígio e influência na localidade.

O Schützenverein Blumenau foi fundado em 2 de dezembro de 1859, com a realização da primeira Schützenfeste passou a concentrar toda a vida social, recreativa e cultural dos 
habitantes da recente colônia. A partir deste momento, a festa passou a ser realizada anualmente (período de Pentecostes), com duração de cerca de três dias, sendo o primeiro reservado para festividades religiosas, o segundo para competições de tiro e o terceiro destinado a um grande baile social. Além das festividades religiosas, das competições de tiro e dos bailes, eram comuns as apresentações teatrais e os desfiles pelas ruas do rei do tiro (ROSSBACH, 2008).

Esses elementos fornecem indícios preliminares de que as associações eram espaços de pertencimento, na medida em que buscavam cultivar a cultura, hábitos e costumes alemães. Ao mesmo tempo, constituíam espaços de distinção entre os habitantes da cidade, dado que a possibilidade de frequentar o Schützenverein Blumenau era reduzida, permitindo aos indivíduos a ele pertencentes alcançar determinado status social. Contudo, é necessário destacar que, em um primeiro momento, o quadro de sócios (54 sócios com uma média de cinco membros por família, portanto 270 pessoas de um total de 944 habitantes) se mostrava bastante heterogêneo em relação ao perfil dos indivíduos, pois existiam médicos, advogados, professores, clérigos, mecânicos, serralheiros, torneiros, oleiros, marceneiros, agricultores e comerciantes. Foi com o crescimento da colônia, o aumento do valor da joia, da mensalidade e pela distância para frequentar o Schützenverein Blumenau que estava situado no centro da cidade, que aos poucos o perfil dos frequentadores foi se transformando e assumindo um caráter mais elitista. Em 20 anos (1883 a 1893), o Schützenverein Blumenau manifestou uma tendência elitista, devido ao processo de urbanização pelo qual a cidade estava passando (PETRY, 1988).

Influenciado pelo desenvolvimento da colônia, o Schützenverein Blumenau também apresenta um aumento do número de admissão em seus anos iniciais, passando de 54 indivíduos pertencentes ao quadro social no ano de 1859 a 106 no ano de 1863. O espaço foi importante para as necessidades sociais, não se restringindo apenas ao tiro ao alvo e às festividades, mas também se constituindo como local para discussão dos problemas comunitários, novas relações sociais e importantes decisões para a vida da comunidade. O Schützenverein Blumenau aos poucos foi ocupando local central na cidade, tornando-se um importante espaço cultural. Suas práticas transcendiam os tiros e as escolhas dos reis, contemplando bailes, jantares, encontros e festividades. Em síntese, a instituição surgiu como uma necessidade social, trazendo novas possibilidades de sociabilidades (PETRY, 1988).

A escolha do rei nos Clubes de Caça e Tiro consistia numa competição na qual o vencedor era coroado numa posterior festividade. Hoffmann e Melo (2014) evidenciam que esses momentos ocupavam importante papel na cultura blumenauense. A competição consistia em disparar uma série de três tiros, com a arma apoiada em um cavalete. No início, o alvo era uma peça de madeira e tinha 20 zonas, ficando posicionada a uma distância de 165 metros dos atiradores. Ao vencedor da prova era dado o direito de disparar dois tiros sobre um alvo de madeira, adornado com letras góticas com o nome da sociedade. 0 evento era finalizado com um baile promovido pelo rei, no qual era oferecido um banquete. No ano seguinte, os atiradores premiados, com suas medalhas costuradas em suas roupas, eram conduzidos pelo capitão, que coordenava todo o cortejo até a residência do rei do ano anterior. Na residência do rei, eram servidos aperitivos pela esposa da majestade. Mulheres e crianças não participavam das competições e do cortejo, apenas do jantar e do baile. Em seguida, o rei era conduzido até seu Clube, posteriormente era dado início ao desfile pelas ruas da cidade.

Rossbach (2008) reforça que, além do primeiro clube de tiro, outras sociedades organizadas foram sendo criadas nos primeiros anos da localidade, corroborando a hipótese 
desenvolvida anteriormente de que foi a partir do desenvolvimento da cidade que começam a surgir outros espaços de convívio. Exemplos disto são as criações do Theaterverein (Sociedade de Teatro Amador) no ano de 1860, da Gesangverein (Sociedade de Canto - Coro) em 1863, do Culturverein (Sociedade de Cultura - Agricultura) também em 1863 e do Turnverein (Sociedade Ginástica) no ano de 1873. A Turnverein durante muitos anos funcionou dentro das instalações do Schützenverein Blumenau, tendo como finalidade a educação dos jovens através da ginástica, corridas e diferentes práticas corporais. A sociedade ginástica ocupou espaço destacado na emergência de uma cultura física entre os jovens de Blumenau. Cabe destacar que todos esses espaços em conjunto se tornam importantes objetos para análises e interpretações de como os indivíduos se comportavam e agiam naquele contexto.

Caracterizada como fenômeno urbano na virada do século XVIII para o XIX, a ginástica, a valorização do exercício físico, estava relacionada ao desenvolvimento de uma sociedade que se afastava do mundo natural, que se encontrava em processo de industrialização e de florescimento das cidades. Ela se desenvolve como possível solução a uma sociedade que o discurso médico e pedagógico afirmava ser decadente, fraca e inerte, em um momento no qual a saúde da população passa a ser um requisito básico para o bem-estar da sociedade (QUITZAU, 2015). Para Moraes e Silva (2011), a emergência dessas práticas corporais só pôde ocorrer devido ao longo processo de transformação atravessado pelas cidades, agora com características mais urbanas, e que se traduziu em novos hábitos, comportamentos e costumes, potencializando o surgimento de novos espaços e instituições.

Acerca da ginástica alemã, que ocupou lugar de destaque na ambiência urbana de Blumenau, ela tem suas raízes no final do século XVIII a partir da publicação da obra de Johann Christoph Friedrich Guts Muths, na qual buscava a exposição dos benefícios do exercício em contraposição aos malefícios do ambiente urbano-industrial e contra um modelo de educação centrada exclusivamente no intelecto. Seus exercícios são divididos em três categorias: exercícios ginásticos, trabalhos manuais e jogos. Outro importante personagem foi Friedrich Ludwig Jahn, que, ao contrário de Guts Muths, cujos fundamentos se aproximavam da medicina e da pedagogia, acreditava na necessidade de fortalecimento da juventude alemã diretamente ligada à necessidade de recuperação de seus territórios e de unificação política. Os elementos que compõem a prática da ginástica jahniana se assemelham aos de Guts Muths, sendo dezessete grupos de exercícios, além de cinco jogos considerados adequados ao Turnen. $O$ espaço de realização dessas práticas deveria ser um local em que prevalecessem a camaradagem, a igualdade e o pertencimento coletivo (QUITZAU, 2016).

Para Vigarello e Holt (2008), a ginástica se traduzia em um lugar de encontro e energia e suas sociedades resultavam em novas formas de mobilização coletiva. Seus dispositivos são específicos, feitos para obedecer uma finalidade e para servir a uma nação. Elas deviam cobrir a totalidade de exercícios físicos higiênicos e/ou educativos, materializando o que deve ser praticado e ensinado aos seus praticantes.

As primeiras sociedades ginásticas fundadas pelos imigrantes alemães no Brasil foram em Joinville, 1858, e no Rio de Janeiro, em 1859. Até a década de 1870 foram fundadas mais duas: a Deutscher Turnverein Porto Alegre, em 1867, que viria a constituir a Turnerbund Porto Alegre (1892), e a Turnverein Blumenau, em 1873 (QUITZAU, 2016). O surgimento da Turnverein Blumenau acontece três anos antes da cidade tornar-se município. 0 ano de 1883 marcou a transformação da colônia em cidade, em um período identificado também como 0 
início da industrialização de Blumenau, destacando-se as firmas têxteis iniciadas pelos irmãos Hering e pela sociedade dos imigrantes Johan Karsten (PETRY, 1988). Estes dados podem sugerir que o surgimento da Turnverein Blumenau pode ter sido uma resposta a um movimento mais amplo, que coincide com o aparecimento dos malefícios produzidos por uma cidade agora com 16.380 habitantes.

Com o desenvolvimento da colônia, alguns fatores foram contribuindo para o surgimento de novos espaços e associações com diferentes finalidades. A expansão das entidades ocorreu devido às grandes distâncias que alguns sócios tinham que percorrer de suas casas ao centro da cidade, bem como os altos valores das mensalidades e joias do Schützenverein Blumenau. Foi neste contexto que surgiram novos Schützenvereine, como o Schützenverein Indaial (1875), Schützenverein Ribeirão Itoupava(1877), SchützenvereinWarnow (1879), Schützenverein Garcia Jordão (1880), Geselligerverein Teutonia (1893), Schützenverein Fidélis (1894), dentre outros. De 1875 a 1899, em um período de vinte e quatro anos, surgiram onze novas sociedades do gênero tiro ao alvo (PETRY, 1988).

Neste sentido, percebe-se que não é somente a quantidade que chama atenção, mas, sim, sua vinculação com o caráter nacional germânico traduzido na noção de Deutschtum (germanidade). Os espaços de cultivo da vida social também funcionavam como locais de atualização de uma identidade marcada pela germanidade e sua recente transformação a partir da relação com a nova pátria (SEYFERTH, 2004).

Esses espaços e possibilidades são elementos fundamentais para a compreensão e entendimento do desenvolvimento da cidade, bem como para a emergência de uma cultura física na população, além de apontar para a efervescência social e cultural que Blumenau atravessava, culminando com novas e diferentes formas de se socializar e se comportar. Os clubes de tiro foram elementos importantes para a vida social, cultural e recreativa dos imigrantes, proporcionando divertimentos, relações sociais e difusão da germanidade. Por meio de festividades religiosas, competições, encontros, festas e bailes, esses espaços se traduzem em complexas redes de significados e interpretações, além de influenciarem nos discursos e nos processos educativos sobre o corpo, tais quais nas diferentes relações sociais, econômicas, políticas e morais pelas quais a cidade atravessava.

Com o surgimento das sociedades, somado à família, à Igreja e às atividades laborais, esse novo indivídu foi se constituindo e se educando. As entidades em especial se constituíram em um importante espaço de educação, na medida em que os participantes deviam se adequar aos mecanismos institucionais e disciplinares. Esse rigoroso conjunto de normas possibilitou aos indivíduos a incorporação de novos hábitos e costumes, além de propiciar acesso a um novo tipo de divertimento. Esses acontecimentos proporcionaram o crescimento do número de frequentadores e de associações, a partir da década de 1890, e indicam a emergência de uma cultura física na cidade. Pelo seu crescimento exponencial, as associações com as práticas voltadas principalmente ao tiro parecem ter sido incorporadas no cotidiano dos habitantes.

Ser rei do tiro, por exemplo, significava um amplo domínio de destrezas físicas e técnicas que culminava com prestígio e reconhecimento social por parte dos habitantes da cidade. As diversas práticas corporais, mais precisamente o tiro, assumem uma centralidade nas configurações sociais daquele período. Para a simples ida ao clube, era necessário um amplo domínio de códigos de etiquetas e condutas, desde simples regras à mesa a serem utilizadas nos jantares de festividades do rei do tiro, perpassando pela escolha adequada das 
vestimentas e/ou até mesmo pela assimilação das regras exigidas para a participação nos jogos. Antes resumidos a família, trabalho e Igreja, os clubes reconfiguram a organização social da cidade. Blumenau não parece ser mais tão tediosa e monótona e aos seus habitantes não restam apenas visitas e conversas com os vizinhos. A cidade, que se industrializava e se modernizava, proporcionava novas formas de divertimentos e de convívio social. As práticas corporais tornaram-se algo corriqueiro entre os blumenauenses.

Passados mais de 150 anos da fundação do primeiro Schützenverein, a presença dos Clubes de Caça e Tiro ainda é bastante presente no dia a dia dos habitantes de Blumenau, representando espaços de resgate e manutenção da cultura germânica. Segundo a Associação dos Clubes de Caça e Tiro, existem atualmente 40 clubes em atividade. Alguns deles bastante antigos, como o Clube de Caça e Tiro Ribeirão Itoupava (1877), o Clube Social Recreativo Caça e Tiro Garcia Jordão (1880), e a Sociedade Recreativa Esportiva Ipiranga (1893). Anteriores a 1900, a cidade ainda conta hoje com dez clubes em funcionamento. Entre as atividades desenvolvidas pelos clubes, atualmente destacam-se o Tiro ao Alvo, Grupos Folclóricos, Bolão, Clube Social, Skat (jogo de baralho de origem alemã), Futebol e a participação na Oktoberfest.

Além da Associação dos Clubes de Caça e Tiro da Cidade de Blumenau, o município conta com um museu específico contendo em seu acervo medalhas, alvos, armas, bandeiras, trajes, painéis textuais, fotografias, faixas de reis e rainhas, constituídos a partir da restauração do antigo Clube Recreativo Esportivo Cultural Concórdia, cuja fundação data de 1899. Trata-se de um importante espaço de manutenção e difusão da história da cidade. $O$ amplo conjunto de acontecimentos e transformações que atravessaram Blumenau, marcadamente por sua influência imigratória alemã, resultou no desenvolvimento econômico, social e cultural da localidade. Essas transformações se traduziram em um conjunto de mudanças que culminaram em novos modos de olhar a cidade, seus tempos e espaços, assim como o próprio corpo.

\section{CONSIDERAÇÕES FINAIS}

Reconhecida nacionalmente como uma cidade de influência alemã em seus costumes, Blumenau ainda cultiva traços estruturais de sua influência imigratória. Na esteira de seu desenvolvimento, a cidade foi se constituindo a partir de uma relação de via de mão dupla, entre os imigrantes e os brasileiros, que se traduz em formas singulares de convívio, educação e construção de tradições.

A emergência de uma cultura física por parte dos habitantes de Blumenau situa-se em um universo amplo de fatos e acontecimentos, os quais apontam para um longo processo de incorporação e assimilação de novas formas de comportamento e socialização. $O$ crescimento da cidade, a transformação de uma vida rural para uma urbana, o aumento no número de habitantes, a forte presença de hábitos e costumes trazidos pelos alemães, além do surgimento de instituições de caráter social e recreativo, culminaram com transformações estruturais na cidade e nos modos de vida dos blumenauenses.

Por meio de encontros, festividades e competições, os clubes de tiro contribuíram para a formação cultural dos habitantes da cidade. Além disso, indicam ter sido a base sólida e potencializadora para a emergência de uma cultura física. Estes espaços e as atividades ali desenvolvidas fornecem indicativos de como os habitantes de Blumenau, ao longo do processo, foram transformando seus hábitos e costumes, o que se traduziu em novas formas 
de se comportar e se relacionar. As festividades, os encontros e as relações sociais se reconfiguraram e 0 uso das armas a partir das práticas de tiro foi sendo transformado pouco a pouco, caminhando da defesa, da segurança, do combate, para a destreza, a pose e a eficiência.

Surge, assim, um amplo conjunto de dispositivos e técnicas, que culminam com formação de novos indivíduos, estes agora situados em uma cidade de caráter menos rural e mais urbano. Porém, é necessário destacar que esse processo não foi linear na medida em que diversas variações e acontecimentos podem ter ocorrido, necessitando de novas interpretações e análises. $O$ presente ensaio permite sugerir novos estudos de modo que aponta a complexidade e potencialidade interpretativa deste objeto de pesquisa, como, por exemplo, o cultivo de uma cultura física a partir das diferentes práticas corporais realizadas na cidade.

\section{REFERÊNCIAS}

ASSMANN, Alice Beatriz; MAZO, Janice Zarpellon. As Schützenvereine- Sociedades de Atiradores - de Santa Cruz do Sul: um tiro certo na história do esporte no Rio Grande do Sul. Esporte e Sociedade, v.7, n.20, p.122-153, 2012.

HOBSBAWM, Eric; RANGER, Terence. A invenção das tradições. São Paulo: Paz e Terra, 1997.

HOFFMANN, Maria Luisa; MELO, Michele. O uso da fotografia na preservação da história dos clubes de caça e tiro de Blumenau. Linguagens, v. 8, n. 2, p. 168-184, 2014.

KIRK, David. Physical culture, Physical education and relational analysis. Sport, Education and Society, v.4, n. 1, p. 63-73, 1999.

LUEBKE, Frederick C. Germans in Brazil: a comparative history of cultural conflict during World War I. Baton Rouge; London: Louisiana State University, 1987.

MACHADO, Ricardo. A invenção da cidade etnizada: História e Memória na Blumenau contemporânea. (1974 - 2002). In: SIMPÓSIO NACIONAL DE HISTÓRIA - ANPUH, 26., 2011. Anais...São Paulo, jul. 2011. p.1-11.

MORAES E SILVA, Marcelo. Novos modos de olhar outras maneiras de se comportar: a emergência do dispositivo esportivo da cidade de Curitiba (1899-1918). 2011. 227f. Tese (Doutorado) - Faculdade de Educação, Universidade Estadual de Campinas, 2011.

NIPPERDEY, Thomas. Verein als soziale Struktur im späten 18. und frühen 19. Jahrhundert. In: BOOCKMAN, Hartmut et al. Geschichtswissenschaft und Vereinswesen im 19. Jahrhundert. Beiträge zur Geschichte historischer Forschung in Deutschland. Göttingen: Vandenhoeck \&Ruprecht, 1972. p.1-44.

PEDRINI, Dalila Maria; MARTINS, Ana Paula. As relações entre mulheres e homens no associativismo civil em Blumenau. In: SHERER-WARREN, I; CHAVES, I. (Orgs). 
Associativismo civil em Santa Catarina: trajetórias e tendências. Florianópolis: Insular, 2004.p. 87-101.

PETRY, Sueli. Os clubes de caça e tiro na região de Blumenau: 1859- 1981. Blumenau: Fundação Casa Dr. Blumenau, 1988.

QUITZAU, Evelise Amgarten. Associativismo ginástico e imigração alemã no sul e sudeste do Brasil (1858-1938). 2016. 242f. Tese (Doutorado)- Faculdade de Educação, Universidade Estadual de Campinas, 2016.

QUITZAU, Evelise Amgarten. Da 'Ginástica para a juventude' a 'A ginástica alemã': observações acerca dos primeiros manuais alemães de ginástica. Revista Brasileira de Ciências do Esporte, v.38, n.2, p.111-118, 2015.

ROSSBACH, Roberto Fabiano. A música em Blumenau no início da colonização alemã (1863-1937).2008. 175f. Dissertação (Mestrado) -Programa de Pós-Graduação em Música, Universidade do Estado de Santa Catarina, 2008.

SCHARAGRODSKY, Pablo Ariel. Miradas médicas sobre la cultura física en Argentina (1880-1970). Buenos Aires: Prometeo, 2014.

SEYFERTH, Giralda. "Identidade étnica, assimilação e cidadania: a imigração alemã e o Estado brasileiro". Revista Brasileira de Ciências Sociais, v.9, n.26, p. 103-122, 1994.

SEYFERTH, Giralda. A ideia de cultura teuto-brasileira: literatura, identidade e os significados da etnicidade. Horizontes Antropológicos, v.10, n. 22, p. 149-197, 2004.

VIGARELLO, Georges. Exercitar-se, jogar. In: VIGARELLO, G.(Org.). História do corpo. Rio de Janeiro: Vozes, 2008.v.1, p.303-400.

VIGARELLO, Georges; HOLT, Richard. O corpo trabalhado: ginastas e esportistas no século XIX. In: CORBIN, A. (Org.). História do corpo. Rio de Janeiro: Vozes, 2008.v.2, p.393-478. 